\title{
VOCAL DIFFERENCES AMONG THE BARRED, CINEREOUS, AND FULVOUS OWLS
}

\author{
NATHAN PIEPLOW, 317 UCB, University of Colorado, Boulder, Colorado \\ 80309; npieplow@gmail.com
}

ANDREW SPENCER, 562 Ellis Hollow Creek Rd., Ithaca, New York 14850

\begin{abstract}
The Cinereous Owl (Strix sartorii), a Mexican pine forest endemic, has long been considered a subspecies of the Barred Owl (S. varia). In this study, we provide the first description and analysis of its vocalizations, which differ markedly from those of the Barred Owl and support the recognition of the Cinereous Owl as a full species. Its rhythmic song consists of seven primary notes and three secondary notes, whereas the analogous song of the Barred Owl consists of six primary notes and two secondary notes, arranged in a different pattern. The rhythmic song of the closely related Fulvous $\mathrm{Owl}$ (S. fulvescens) has only five or six primary notes, versus seven in that of the Cinereous Owl. The Cinereous Owl's song is much lower in pitch than the Fulvous Owl's. Unlike the Fulvous Owl but like the Barred Owl, the Cinereous Owl also has a distinctive and frequently deployed series song.
\end{abstract}

In 1873, Robert Ridgway described a subspecies of the Barred Owl that he named Syrnium nebulosum var. sartorii in honor of Carl Christian Sartorius, a German naturalist who collected the type specimen on his hacienda at Mirador in the mountains of Veracruz (Baird and Ridgway 1873:200). Ridgway wrote,

This form is very different from var. fulvescens ... from Guatemala. I have seen a specimen of the latter collected by Van Patten, and now in the Museum of the Boston Society. The var. nebulosum stands between the two, being intermediate in nearly all its characters.

The "var. fulvescens" to which Ridgway referred was the Fulvous Owl, now known as Strix fulvescens. Ridgway's "var. nebulosum" was the Barred Owl of the United States and Canada, now known as Strix varia. Ridgway considered all three of these taxa conspecific, but soon thereafter authors such as Sharpe (1875) began to recognize the Fulvous Owl as a separate species, on the basis of its much smaller size, its distinctly brighter coloration, and, eventually, its very different voice.

Most authors have continued to consider sartorii to be a subspecies of the Barred Owl, despite differences in range (e.g., Mazur and James 2000), habitat (e.g., Binford 1989), and genetics (Barrowclough et al. 2011). This likely stems from the dearth of information available on the taxon. As recently as 2015, no photographs of sartorii had been published, and its voice remained undescribed.

We here present an analysis showing the voice of the Cinereous Owl to be quite different from the voices of the Barred and Fulvous Owls. The vocal differences, along with the genetic differences (Barrowclough et al. 2011), support recognizing the Cinereous Owl as a full species.

\section{Vocal Terminology and Song Structure in the Genus Strix}

The songs of owls in the genus Strix differ in their rhythmic patterns. They tend to consist of two types of notes: primary notes that are loud and clearly distinct (i.e., separated by obvious pauses), and secondary notes that are generally softer and shorter than the primary notes. Secondary notes are 
also more variable; in different individual owls within a species, they may be clearly distinct from the primary notes or connected to them, and they may range from obvious to nearly absent. When connected to a primary note, they create the impression of a second syllable-for example, turning a primary note "HOO!" into something that sounds like "aHOO!"

Many owls in the genus Strix, including the Barred Owl (Mazur and James 2000, Odom and Mennill 2010) and the Spotted Owl (S. occidentalis; Gutiérrez et al. 1995), have two song types: a "rhythmic song" with primary and secondary notes arranged in a species-specific syncopated rhythm, and a "series song" with mostly primary notes in a steadier but still distinctive rhythm.

\section{METHODS}

In 2015, on Cerro San Juan in Nayarit with Carlos Sanchez, we obtained photographs of a living Cinereous Owl and audio recordings of its voice. We compared our audio recordings of this single individual to those of Barred Owls from the United States and Fulvous Owls from Central America and southern Mexico. We identified rhythmic and series songs in the Barred Owl recordings by comparison with published spectrograms (e.g., McGarigal and Fraser 1985, Mazur and James 2000, Pieplow 2019). Using qualitative comparison of spectrograms and our admittedly meager information about the behavioral context of the songs in our Cinereous Owl recordings, we identified rhythmic and series songs in the Cinereous Owl that we believe to be analogous to the respective songs of the Barred Owl. Because the songs of the Cinereous Owl in our recordings differ obviously from the typical songs of Barred Owls in number and rhythm of notes, our comparison of the two species did not include a statistical component.

We performed a statistical analysis comparing the songs of the Cinereous Owl with those of the Fulvous Owl. Our sample of Fulvous Owls $(n=88)$ included every recording of the species available at www.xeno-canto.org or in the Macaulay Library archive, and a few recordings that we had made. In some recordings, two individuals were audible. We assumed that different recordings were of the same individual or pair if they were made at the same or similar locations in the same year. Thus, we estimated that this sample represented a minimum of 61 different individuals, including 16 apparent male-female pairs. We defined a male-female pair as a pair of birds vocalizing on the same recording in which one bird was higher-pitched than the other. We assumed that the higher-pitched birds in these pairings are females, as has been reported in other species of Strix (e.g., Mazur and James 2000, Odom and Mennill 2010). This assumption may not always hold, as some of the recordings might have been of countersinging males.

Our comparison of Fulvous and Cinereous Owl songs included only the rhythmic songs, because we could not identify any series songs in our Fulvous Owl sample. In each recording of both species, we used visual analysis of spectrograms in Raven Pro software (Cornell Bioacoustics Research Program, Cornell Laboratory of Ornithology) to measure the number of notes and the peak frequency of each individual's song on the recording, using the single instance of song with the highest amplitude. In one recording of an apparent pair duet, the female's song was too faint to be measured accurately. 
Recordings archived at www.xeno-canto.org are indicated with the abbreviation XC, those in the Macaulay Library archive with the abbreviation ML. Terminology used to describe sounds follows that of Pieplow (2019).

\section{RESULTS}

\section{Comparison of Rhythmic Songs}

The rhythmic songs of the Barred Owl and the Cinereous Owl are very different. The Cinereous Owl's rhythmic song is much more similar to the Fulvous Owl's, but it is lower and contains more notes.

In the Barred Owl, the rhythmic song consists of six primary notes and two secondary notes (Figure 1A). The secondary notes are inserted before the third and sixth primary notes. In addition, the sixth primary note is drawn out at the end, creating the impression of an additional falling syllable. The result sounds like "HOO HOO! aHOO! HOO HOO! aHOO-wah!" (or the familiar "Who cooks for you? Who cooks for you-all?"). This is the most common song of the Barred Owl; McGarigal and Fraser (1985) recorded it in 20 of 25 instances in which Barred Owls responded to broadcast of their species' vocalizations (80\%).

In the Fulvous Owl, the rhythmic song consists of five primary notes and three secondary notes (Figure 1C). The secondary notes are inserted before the first, second, and fourth primary notes, in a pattern that sounds like "aHOO! aHOO HOO! aHOO HOO!" The first secondary note is reduced or absent in some birds. This is the most common vocalization of the species; it appears in every recording of the Fulvous Owl that we were able to locate $(n=88)$.

The rhythmic song we recorded from the Cinereous Owl in Nayarit (ML 21681321, Figure 1B) consisted of seven primary notes and three secondary notes. As in the Fulvous Owl, the secondary notes were inserted before the first, second, and fourth primary notes. The first secondary note was reduced and nearly absent. The pattern thus sounded like the Fulvous Owl's, but with two additional loud hoots at the end: "aHOO! aHOO HOO! aHOO HOO! HOO! Hoo." The final note was lower than the rest in both frequency and amplitude.

The frequency of the Cinereous Owl's rhythmic song fell outside the range of variation we measured in Fulvous Owl songs. The peak frequencies of the presumed female Fulvous Owls in our sample (mean $696 \mathrm{~Hz}$, range 648-772 $\mathrm{Hz}, \mathrm{SD}=32 \mathrm{~Hz}, n=15$ ) averaged substantially higher than the peak frequencies of the presumed males (mean $563 \mathrm{~Hz}$, range 505-655 Hz, SD $=46 \mathrm{~Hz}$, $n=16$ ). Thus the ranges overlapped only slightly, and an independent-sample two-tailed $t$-test found the difference of the means to be highly significant $\left(t_{29}=-9.22, p<0.001\right)$.

We measured the peak frequency of the Cinereous Owl's rhythmic song as $453 \mathrm{~Hz}(n=1)$. This is more than $50 \mathrm{~Hz}$ below the lowest recorded peak frequency in our Fulvous Owl sample. Therefore, we think it likely that the Cinereous Owl we recorded was a male.

The number of notes in the rhythmic song represents another difference between the Cinereous and Fulvous Owls. Most rhythmic songs of the Fulvous Owl in our sample consisted of five primary notes $(n=61)$, but we found two examples of six-note songs (ML 127222, ML 27299401). We found zero examples of seven-note rhythmic songs like that of the Cinereous Owl in Nayarit. 

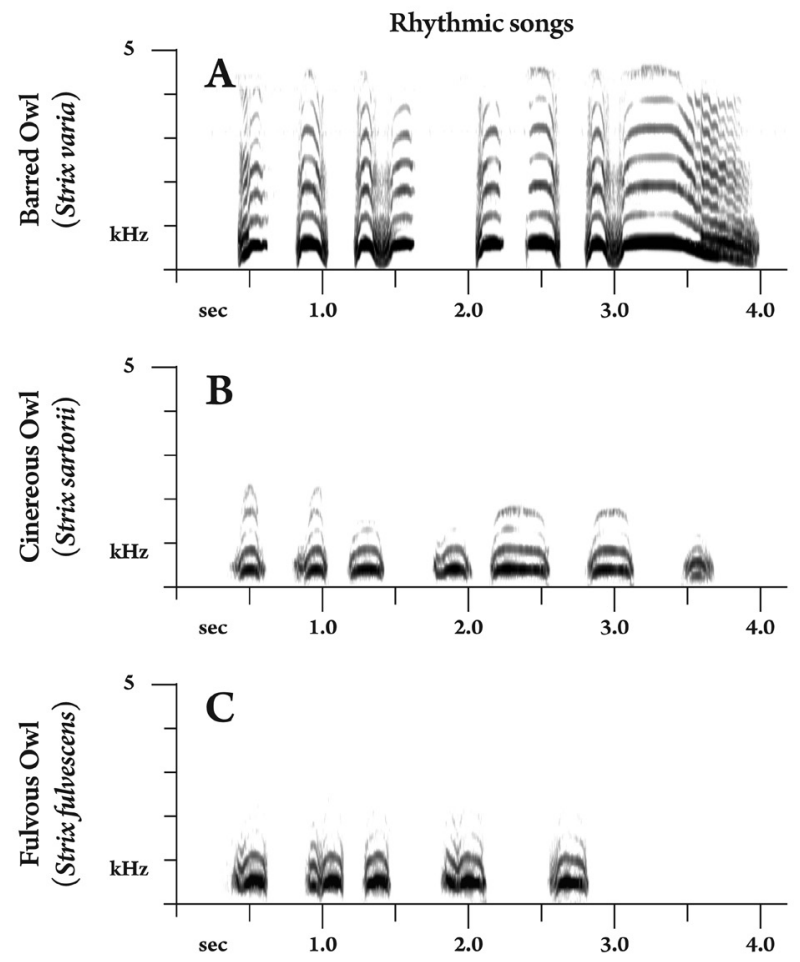

Figure 1. (A) Rhythmic song of a Barred Owl (Strix varia), Arkansas, 20 March 2005 (Gerrit Vyn and Benjamin Clock, ML 128926). (B) Rhythmic song of a Cinereous Owl (S. sartorii), Rancho La Noria, Nayarit, Mexico, 4 June 2015 (Nathan Pieplow, ML 21681321). (C) Rhythmic song of a Fulvous Owl (S. fulvescens), Finca Las Nubes, Guatemala, 8 March 2013 (Mike Nelson, XC 125759). Spectrograms have been graphically edited to remove echo and insect noise. Note that the number of visible harmonics depends greatly on the distance from the microphone to the bird.

\section{Comparison of Series Songs}

The series songs of the Barred and Cinereous Owls are just as distinct as their rhythmic songs, while a series song has not been reported in the Fulvous Owl.

The series song of the Barred Owl (Figure 2A) consists of a series of six to nine primary notes that rises slightly but consistently at an even pace before ending in a slightly modulated falling note ("aHOO-wah!") that resembles the final note of the rhythmic song. Pieplow (2019) described it as "who who who who WHO WHO for YOU." In the Barred Owl the series song is nearly as common as the rhythmic song. McGarigal and Fraser (1985) recorded it in 14 of 25 instances in which Barred Owls responded to broadcast of their species' vocalizations ( $56 \%$ ).

The series song of the Cinereous Owl (e.g., ML 21688921; Figure 2B) 

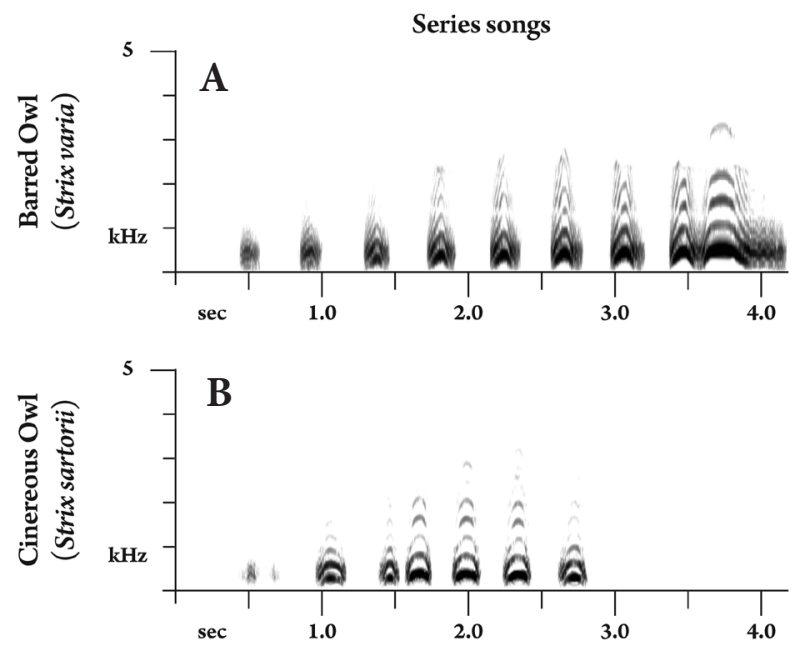

Figure 2. (A) Series song of a Barred Owl, West Virginia, 3 May 2010 (Andrew Spencer, XC 48645). (B) Series song of a Cinereous Owl, Rancho La Noria, Nayarit, Mexico, 5 June 2015 (Nathan Pieplow).

consists of six to nine primary notes introduced by one or two softer, lower secondary notes. The first few primary notes are not evenly spaced; the gap between the first and second is slightly elongated, and the gap between the second and third is slightly shortened. The remaining three or four notes are loud and evenly spaced, all on the same pitch, except that the last one or two are slightly lower and softer. This song differs from the Barred Owl's series song in its syncopated beginning and its uniformity in pitch. In the Barred Owl's series song, the highest and loudest notes are at the end, while in the Cinereous Owl's, the highest and loudest notes are in the middle.

We also recorded songs from the Cinereous Owl that appear intermediate between the rhythmic and the series song, beginning with a pattern similar to the "HOO! aHOO HOO!" from the start of the rhythmic song and ending with the three or four evenly spaced notes from the end of the series song. Perhaps this version represents an excited, extended variant of the rhythmic song.

Mark Stackhouse (pers. comm.) reports that in approximately 20 attempts to draw responses from Cinereous Owls on Cerro San Juan since 2015, he has found that the birds respond more quickly and aggressively to the series song than they do to the rhythmic song. They almost always give the series song in response to broadcast of either song type. His experience matches our experience in 2015. An adult bird gave unsolicited rhythmic songs at the beginning of our encounter, but after we recorded the rhythmic song and played it back, the owl approached giving only series songs and intermediate songs. We hypothesize that the Cinereous Owl's rhythmic song serves more of an advertising function, while the series song and intermediate song serve more of an aggressive, territorial function.

A series song is unreported in the Fulvous Owl. It does not occur in any of 
the 88 audio recordings of the Fulvous Owl that we were able to review. When Fulvous Owls respond aggressively to broadcast of the rhythmic, both males and females give that same song. In high agitation, they may give the rhythmic song several times in a row with one or two nasal barking notes in between (XC 125755; ML 78779481). Pairs responding together to recordings of such songs often sing overlapping songs that together can give the impression of a series song, but careful analysis of recordings reveals that in all cases these duets consist of typical rhythmic songs from each member of the pair, with occasional nasal barks between songs. In extreme agitation, Fulvous Owls may give variable barks that grade into wails (XC 302861, around 1:38). The absence or rarity of a series song constitutes a major difference between the vocal repertoire of the Fulvous Owl and that of the Barred or Cinereous Owl.

\section{Other Vocalizations of the Cinereous Owl}

Barred Owls are well known for the cackling and wailing notes they give during excited pair duets, known as "caterwauling." The excited pair duets of the Fulvous $\mathrm{Owl}$ are more subdued, though the occasional barking notes do recall those of the Barred Owl. The pair duets of Cinereous Owl have not yet been recorded.

We recorded a shriek from a begging young Cinereous Owl in 2015 (ML 21689041). It rose distinctly in pitch and lasted about 1 second. It resembles the begging shrieks of the Barred Owl (ML 4549) and the Fulvous Owl (XC 42718). We also recorded several other sounds during a feeding of the same juvenile by an adult Cinereous Owl (ML 21689041, XC 250345). The feeding took place out of our sight, but it seems likely that both the adult and the juvenile gave chitter calls, as almost all North American owl species do in close family contact. We also heard a low-pitched overslurred wail that was apparently given by the adult.

\section{CONCLUSIONS}

It seems clear that the Cinereous Owl deserves species status. Vocalizations in owls are presumed to be innate (e.g., Gahr 2000), are typically speciesspecific, and discriminate closely related species (Wiens et al. 2011).

The Cinereous Owl also differs strikingly from the Barred Owl in range, with a gap of $700 \mathrm{~km}$ between the southernmost area occupied by the Barred Owl in Texas (Mazur and James 2000) and the northernmost specimen location of the Cinereous Owl in San Luis Potosí (Louisiana Museum of Natural History specimens 15053, 15054). It occupies a very different habitat, being restricted to high-elevation pine and pine-oak forests. The Cinereous Owl is closer to the Fulvous Owl in vocalizations, range, and habitat, but is physically quite distinct from it, sharing the Barred Owl's larger size and grayish coloration.

The distinctness of the Cinereous Owl is supported by genetic evidence. Barrowclough et al. (2011) called for elevating the Cinereous Owl to species status on the basis of genetic differentiation. J. Maley and J. Salter at the Moore Laboratory of Zoology sequenced the mitochondrial DNA of three Cinereous Owl specimens from Guerrero and confirmed that they form a clade separate from other species of Strix (unpubl. data).

We hope that the recognition of the Cinereous Owl as a full species endemic to Mexico will spur interest in its study and conservation. Very little 
is currently known of its biology or the reasons for its apparently precipitous decline (Pieplow et al. 2020).

\section{ACKNOWLEDGMENTS}

We thank Manuel Grosselet, Alberto Martínez, Jose Luis Mena, Bob McGuire, and Carlos Sanchez for accompanying us on searches in the field. Steve N. G. Howell was instrumental in our successful 2015 effort to document the Cinereous Owl in Nayarit. James Maley and Jessie Salter provided feedback on early drafts and generously shared their unpublished results. We also thank Ned Brinkley, Leonardo Chapa Vargas, Víctor L. Güitrón, Gerardo Hernández Vázquez, Dan Lane, Roberto Pedraza Ruiz, Michael Retter, Fernando Romo, Chris Sharpe, Mark Stackhouse, Ingrid Tello-López, and Bernardillo Villa Bonilla for helpful discussion about Strix owls and sites for nocturnal surveys in Mexico.

We thank George Barrowclough, R. J. Gutiérrez, and Karan Odom for their technical reviews of our manuscript.

\section{LITERATURE CITED}

Baird, S. F., and Ridgway, R. 1873. On some new forms of American birds. Bull. Essex Inst. 5(12):197-201.

Barrowclough, G. F., Groth, J. G., Odom, K. J., and Lai, J. E. 2011. Phylogeography of the Barred Owl (Strix varia): Species limits, multiple refugia, and range expansion. Auk 128:696-706; doi.org/10.1525/auk.2011.11057.

Binford, L. C. 1989. A distributional survey of the birds of the Mexican state of Oaxaca. Ornithol. Monogr. 43; doi.org/10.2307/40167673.

Gahr, M. 2000. Neural song control system of hummingbirds: Comparison to swifts, vocal learning (songbirds) and nonlearning (suboscines) passerines, and vocal learning (Budgerigars) and nonlearning (dove, owl, gull, quail, chicken) nonpasserines. J. Comp. Neurol. 426:182-196; doi.org/10.1002/10969861(20001016)426:2<182::AID-CNE2>3.0.CO;2-M.

Gutiérrez, R. J., Franklin, A. B., and LaHaye, W. S. 1995. Spotted Owl (Strix occidentalis), in The Birds of North America (A. F. Poole and F. B. Gill, eds.), no. 179. Acad. Nat. Sci., Philadelphia; doi.org/10.2173/bna.179.

Mazur, K. M., and James, P. C. 2000. Barred Owl (Strix varia), in The Birds of North America (A. F. Poole and F. B. Gill, eds.), no. 508. Birds N. Am., Inc., Philadelphia; doi.org/10.2173/bna.508.

McGarigal, K., and Fraser, J. D. 1985. Barred Owl responses to recorded vocalizations. Condor 87:552-553; doi.org/10.2307/1367961.

Odom, K., and Mennill, D. J. 2010. A quantitative description of the vocalizations and vocal activity of the Barred Owl. Condor 112:549-560; doi.org/10.1525/ cond.2010.090163.

Pieplow, N. 2019. Peterson Field Guide to Bird Sounds of Western North America. Houghton Mifflin Harcourt, Boston.

Pieplow, N., Spencer, A., Sánchez, C., and Grosselet, M. 2020. Changes in the status and distribution of the Cinereous and Fulvous owls in Mexico. W. Birds 51: in press.

Sharpe, R. S. 1875. Catalogue of the Birds in the British Museum, vol. 2: Striges, or nocturnal birds of prey. Br. Mus., London.

Wiens, J. D., Anthony, R. G., and Forsman, E. D. 2011. Barred Owl occupancy surveys within the range of the Northern Spotted Owl. J. Wildlife Mgmt. 75:531-538; doi.org/10.1002/jwmg.82. 